\title{
TEXTURE AND YOUNG'S MODULUS ANISOTROPY IN NANOSTRUCTURED COPPER
}

\author{
I.V. ALEXANDROV ${ }^{a, *}$, V.N. SEREBRYANY ${ }^{\mathrm{b}}$, \\ L.N. SARVAROVA ${ }^{a}$, M.V. ALEXANDROVA ${ }^{c}$ \\ and R.Z. VALIEV ${ }^{\mathrm{a}}$
}

${ }^{a}$ Institute of Physics of Advanced Materials, Ufa State Aviation Technical University, K. Marksa 12, 450000 Ufa, Russia; ${ }^{b}$ All-Russia Institute of Light Alloys, 121596 Moscow, Russia; ${ }^{c}$ Insitute for Superplasticity of Metals, Russian Academy of Sciences, S. Khalturina 39, 450001 Ufa, Russia

(Received in final form 28 September 1997)

It was shown that in ultrafine-grained nanostructured $\mathrm{Cu}$ processed by severe plastic deformation and subjected to cold rolling and annealing, the level and character of Young's modulus anisotropy is significantly different from values corresponding to cold rolled and annealed coarse-grained $\mathrm{Cu}$. The crystallographic texture formation processes are investigated in these states in parallel. The comparative study of the elastic behaviour and crystallographic texture lets us draw conclusions concerning the leading role of not only developing crystallographic texture but a specific defect structure of grain boundaries as well in the formation of unusual elastic properties of ultrafine-grained materials processed by severe plastic deformation.

Keywords: Texture; Young's modulus anisotropy; Ultrafine-grained structure; $\mathrm{Cu}$

\section{INTRODUCTION}

It is well known that large plastic deformations can significantly refine the structure of materials (Langford and Cohen 1969; Rybin, 1987; Pavlov, 1989). However, the structures obtained are usually of a cellular type with low-angle misorientations. The recent studies (Valiev et al., 1993; Valiev, 1997) confirmed the possibility to apply severe plastic

\footnotetext{
* Corresponding author.
} 
deformation procedure, i.e. large plastic deformations under high applied pressure conditions, for fabrication of ultrafine-grained, nanostructured materials with high-angle grain misorientations.

It was shown that the processed ultrafine-grained materials can possess a number of unique attractive mechanical and physical properties (Valiev et al., 1993; Valiev, 1997). Among them one should note record strength at sufficiently high ductility, low temperature and high rate superplasticity etc. Noticeable changes in properties which are usually nonsensitive to structure parameters such as Curie and Debye temperature, elastic moduli, saturation magnetisation, etc. are also typical for the given materials. For example, the investigations conducted (Akhmadeev et al., 1992; Akhmadeev et al., 1993) showed that the Young's modulus in $\mathrm{Cu}$ and $\mathrm{Ni}$ is lower (by almost 13\%) than in the corresponding coarse-grained materials.

There are various point of views on causes attributed for defects of the Young's modulus in ultrafine-grained materials. Among them one can mention the influence of internal elastic stresses, lattice dislocations as well as the presence of a large volume fraction of grain boundaries (Akhmadeev et al., 1992; Akhmadeev et al., 1993; Lebedev et al., 1996a,b). An assumption that a non-equilibrium state of grain boundaries attributed to high density of grain boundary dislocations leading to the formation of a low modulus phase near grain boundaries could be the main reason for a decrease of the Young's modulus in ultrafine-grained materials produced by severe plastic deformation (Valiev et al., 1994b) was also put forward. On the other hand, it is known that severe plastic strains accompanied by the formation of a crystallographic texture (Alexandrov et al., 1996a) being the main factor determining the level and anisotropy of elastic properties in coarsegrained materials (Davies, 1976).

It is well known that during cold rolling of coarse-grained $\mathrm{Cu}$ a deformation texture called "a texture of a pure metal" is usually formed; this texture being typical for the majority of metals with fcc lattice (Bunge, 1969; Pospiech and Lücke, 1975). During recrystallization annealing, a transformation of this texture to a sharp cubic one is observed (Öztürk, 1978). At the same time noticeable changes in the level and anisotropy of the Young's modulus occur in the plane of rolling (Davies, 1976; Ruberg, 1978; Alexandrov and Davies, 1985). Under definite conditions of cold rolling and annealing, analogous 
processes of texture formation are observed in ultrafine-grained $\mathrm{Cu}$ produced by severe plastic deformation (Alexandrov et al., 1996a). Thus, one can expect that crystallographic texture influences the level and anisotropy of the Young's modulus in ultrafine-grained materials produced by severe plastic deformation. But this question requires further investigations.

The present paper deals with investigation of processes of texture formation and definition of their role in formation of Young's modulus anisotropy after cold rolling and following annealing of ultrafinegrained $\mathrm{Cu}$ processed by severe plastic deformation and their comparison with analogous investigations of coarse-grained $\mathrm{Cu}$.

\section{MATERIAL AND METHOD}

A coarse-grained $\mathrm{Cu}$ with a grain size of more than $10 \mu \mathrm{m}$ and ultrafinegrained $\mathrm{Cu}$ were taken as initial states for following rolling and annealing. The coarse-grained $\mathrm{Cu}$ in a form of a cylindrical ingot, $20 \mathrm{~mm}$ in diameter and $80 \mathrm{~mm}$ in length, was cut from the as-received $\mathrm{Cu}$ rod $(99.98 \%)$. The ultrafine-grained $\mathrm{Cu}$ was processed by severe plastic deformation via equal channel angular pressing. During this processing an ingot was pressed at room temperature through the die with an angle of intersection of two channels of $90^{\circ}$ (Fig.1). Following the first pressing, the sample was pressed again through the same die several times. A relationship is available to estimate the strain in the sample on a single passage through a die (Segal et al., 1981; Iwahashi et al., 1996;

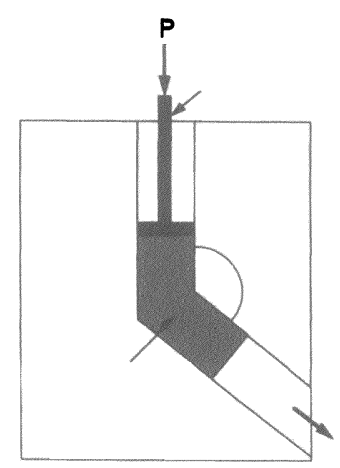

FIGURE 1 Scheme of ECA pressing. 
Valiev, 1997) and it follows from this relationship that a single pass in the present experiments gives a strain of $\sim 1$. Equal channel angular pressing was conducted in 16 passes. The previous investigations of samples subjected to such deformation processing showed that equiaxial granular structure with a mean grain size of $100-200 \mathrm{~nm}$ was formed in them (Valiev et al., 1994a,b; Valiev, 1997).

Initial ingots with ultrafine-grained and coarse-grained structure were subjected to cold rolling at room temperature with a total degree of compression of $83 \%$. The degree of compression at each pass did not exceed $5 \%$. The produced flat square samples, $20 \times 20 \mathrm{~mm}$ in dimension and $1 \mathrm{~mm}$ in thickness, were annealed in vacuum (pressure of residual gas $-6.65 \times 10^{-3} \mathrm{~Pa}$ ) at temperatures of $50^{\circ} \mathrm{C}, 100^{\circ} \mathrm{C}, 200^{\circ} \mathrm{C}$ and $250^{\circ} \mathrm{C}$ correspondingly for each sample during $30 \mathrm{~min}$ with the aim to receive different structural states.

The formed texture was characterised by means of orientation distribution functions (ODFs) obtained by a modified method of maximum entropy (Alexandrov et al., 1996a; Wang et al., 1996). Non-complete pole figures (111), (200), (220) obtained in a reflection mode from samples inclined up to $80^{\circ}$ were used as initial data for the calculation of ODFs.

Taking into account the small size of the produced samples, the value and anisotropy of the Young's modulus in the plane of rolling were calculated from the constants of single crystal elasticity and the volume fraction of grains in any orientation (Bunge, 1968; 1969). The calculations were made on the basis of known theories of Voigt (similar deformation of each grain), Reuss (similar strains in each grain) and Hill. As known, these theories provide upper and lower estimation of calculated values of the Young's modulus, as well as their averaged value, respectively (Davies, 1976).

For calculation of anisotropy of the Young's modulus it is sufficient to use ODF coefficients $C_{l}^{\mu \nu}$ with the lower index $l=4$ (Bunge, 1968; 1969). ODF coefficients $C_{4}^{11}$ and $C_{4}^{12}$ were determined using the well proved (Serebryany, 1994; 1996; Alexandrov et al., 1996b) ultrasonic method of combining the velocities of longitudinal and shear bulk waves (Allen and Sayers, 1984) within the framework of Sayer's model (Sayers, 1982). In this case the measurement of the density and thickness of the investigated samples was not required. The phase velocity of the ultrasonic waves was judged by time delays, i.e., the time of ultrasonic wave propagation between the primary and the $n$th reflection signal. 
Time delays were measured in an echo-pulse mode using acoustic piezoelectric transducers with a resonance frequency of $7-10 \mathrm{MHz}$. These transducers sent longitudinal and two shear ultrasonic waves in a direction normal to the sheet rolling plane with the polarization planes of the waves orientated along and across the rolling direction, respectively. The instrumental error of the time delay measurements did not exceed $1 \mathrm{~ns}$. Ultrasonic measurements were conducted on the basis of three independent measurements for each point. The detailed description of the calculation of the coefficients $C_{4}^{11}$ and $C_{4}^{12}$ is given in the work by Serebryany $(1994,1996)$.

For the calculation of the coefficient $C_{4}^{13}$ it was assumed that the investigated textures can be presented as a set of separate texture components with Gaussian scattering with respect to some ideal orientations. The components $\{112\}\langle 111\rangle,\{123\}\langle 634\rangle,\{110\}\langle 112\rangle,\{100\}\langle 001\rangle$, $\{131\}\langle 323\rangle,\{120\}\langle 001\rangle$ being the most typical for textures of rolling and recrystallization of pure fcc metals were taken as such components. The ODF coefficient $C_{4}^{13}$ was calculated from the relationship (Serebryany, 1996):

$$
C_{l}^{\mu \nu}=\sum_{i=1}^{N} V_{i}(\mathbf{g}) \times C_{l}^{\mu \nu}(\boldsymbol{g}),
$$

where $N, V_{i}(g)$ and $C_{l}^{\mu \nu}(\boldsymbol{g})$ are the number of ideal orientations $\boldsymbol{g}$, their volume fraction and ODF coefficient, respectively. The volume fraction of the considered orientations was determined by calculating Eq. (1) in respect to unknown $V_{i}(g)$ by the method of least squares using iterative procedures. During calculation, the coefficients $C_{4}^{11}$ and $C_{4}^{12}$, estimated on results of ultrasound measurements were substituted in the left part of the given equation.

The total relative error in determination of the Young's modulus did not exceed $3 \%$.

\section{EXPERIMENTAL RESULTS}

The conducted investigations showed that ODF of the cold rolled ultrafine-grained $\mathrm{Cu}$ processed by severe plastic deformation (Fig. 2(a)) was similar to ODF of the cold rolled coarse-grained $\mathrm{Cu}$ (Fig. 2(b)) and characterised by texture components typical for the texture of the latter 
$\mathrm{Cu}$, i.e. by $\{112\}\langle 111\rangle,\{123\}\langle 634\rangle$ and $\{110\}\langle 112\rangle$ (Kallend, 1970; Pospiech and Lücke, 1975; Öztürk, 1978; Ruberg, 1978; Alexandrov and Davies, 1985). In the case of the cold rolled ultrafine-grained $\mathrm{Cu}$ the orientation density is decreased near orientation $\{110\}\langle 112\rangle$ but increased near other characteristic orientations.

Low temperature annealing at $250^{\circ} \mathrm{C}$ for $30 \mathrm{~min}$ led to a qualitative change in a character of the crystallographic texture both in the ultrafine-grained (Fig. 3(a)) and coarse-grained $\mathrm{Cu}$ (Fig. 3(b)). The crystallographic texture typical for the coarse-grained $\mathrm{Cu}$ in a state after cold rolling + annealing was formed in both cases. The formed texture is described by the ideal orientation $\{001\}\langle 100\rangle$ (Davis et al., 1975). It should be noted that after low temperature annealing the intensity of the texture maxima in the case of the cold rolled ultrafine-grained $\mathrm{Cu}$ is

(a)

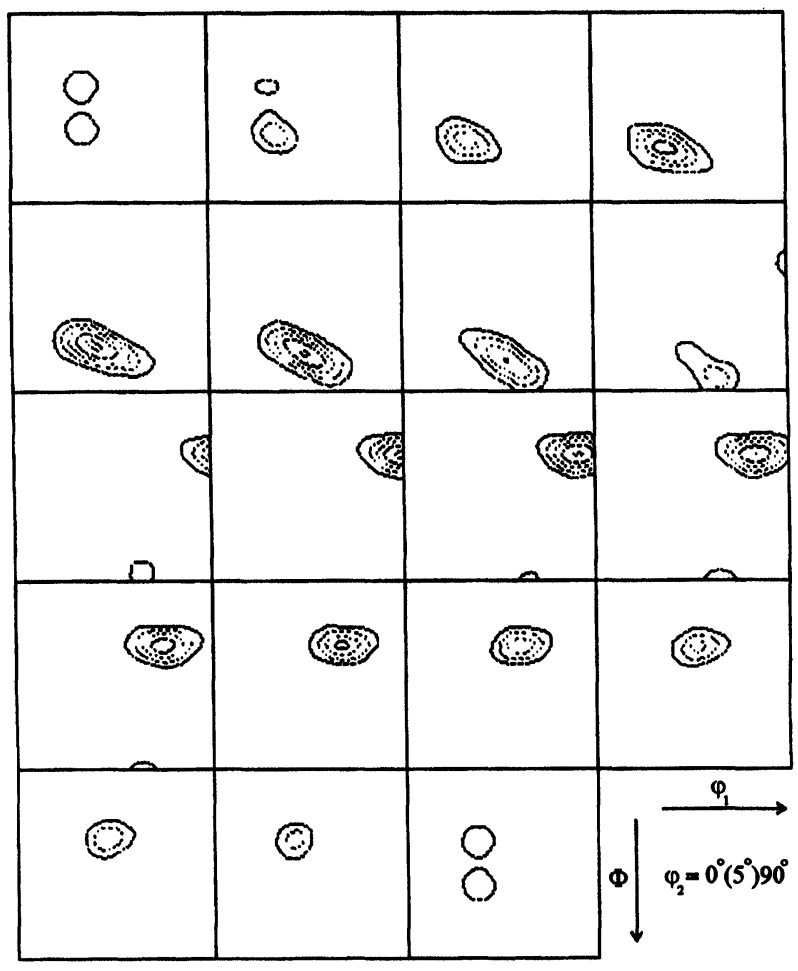

Isolines: $4,8,12,16,20$

FIGURE 2(a) 
(b)

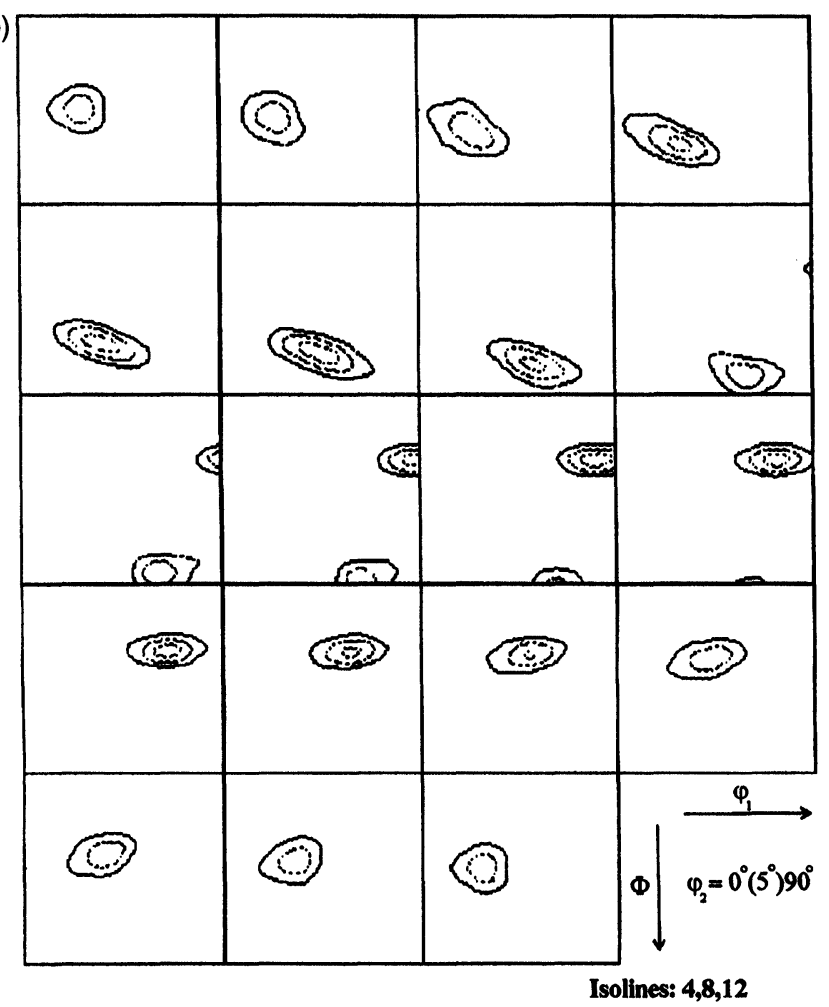

FIGURE 2(b)

FIGURE 2 ODF of the cold rolled Cu: ultrafine-grained (a), coarse-grained (b).

higher than in the cold rolled coarse-grained $\mathrm{Cu}$ by a factor of 2 . An analogous tendency was recently revealed by Mishin et al. (1996).

The results of calculations of the Young's modulus level and its anisotropy in the rolling plane after cold rolling and low temperature annealing at different temperatures are given in Figs. 4 and 5 for cold rolled samples of ultrafine-grained and coarse-grained $\mathrm{Cu}$, respectively.

In Fig. 5(a) for the cold rolled coarse-grained $\mathrm{Cu}$ one can see distinct maxima in the rolling direction and the transverse one. Such anisotropy of elastic properties has already been observed in the literature (Bunge, 1969; Davies, 1976). During low temperature annealing the character of Young's modulus anisotropy in the cold rolled coarse-grained $\mathrm{Cu}$ has changed (Fig. 5(a)-(e)). Instead of the distinctly pronounced anisotropy 
of the Young's modulus corresponding to the texture of cold rolling (Fig. 5(a)), an almost isotropic state was formed after annealing at $250^{\circ} \mathrm{C}$ (Fig. 5(e)). A similar character of the Young's modulus anisotropy has already been observed hitherto (Alexandrov and Davies, 1985).

The curves of Young's modulus changes obtained on the basis of the theories of Voigt, Reuss and Hill in each case considered were similar to each other. And in each case values corresponding to the Voigt theory were maximum while values corresponding to the Reuss theory were minimum. Thus, the possible limiting values of the Young's modulus were determined. Values corresponding to the Hill theory were intermediate.

Contrary to the above results obtained during investigation of the cold rolled coarse-grained $\mathrm{Cu}$ (Fig. 5(a)), the calculations made for the cold rolled ultrafine-grained $\mathrm{Cu}$ revealed absolutely different character

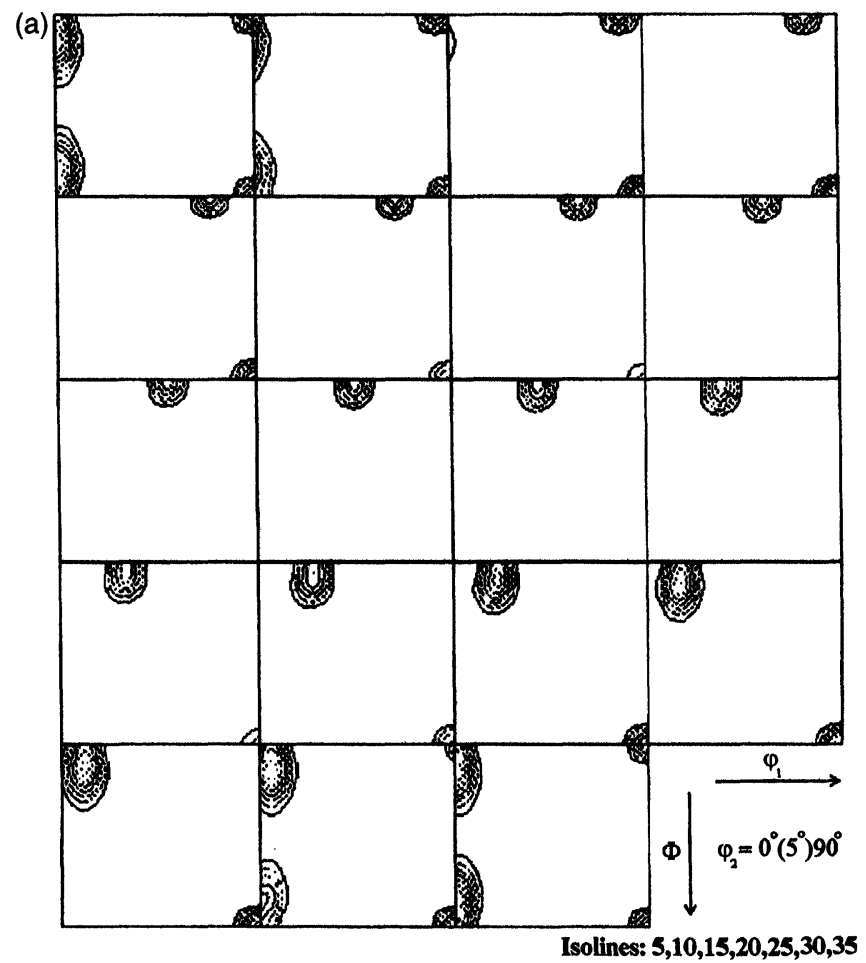

FIGURE 3(a) 
(b)

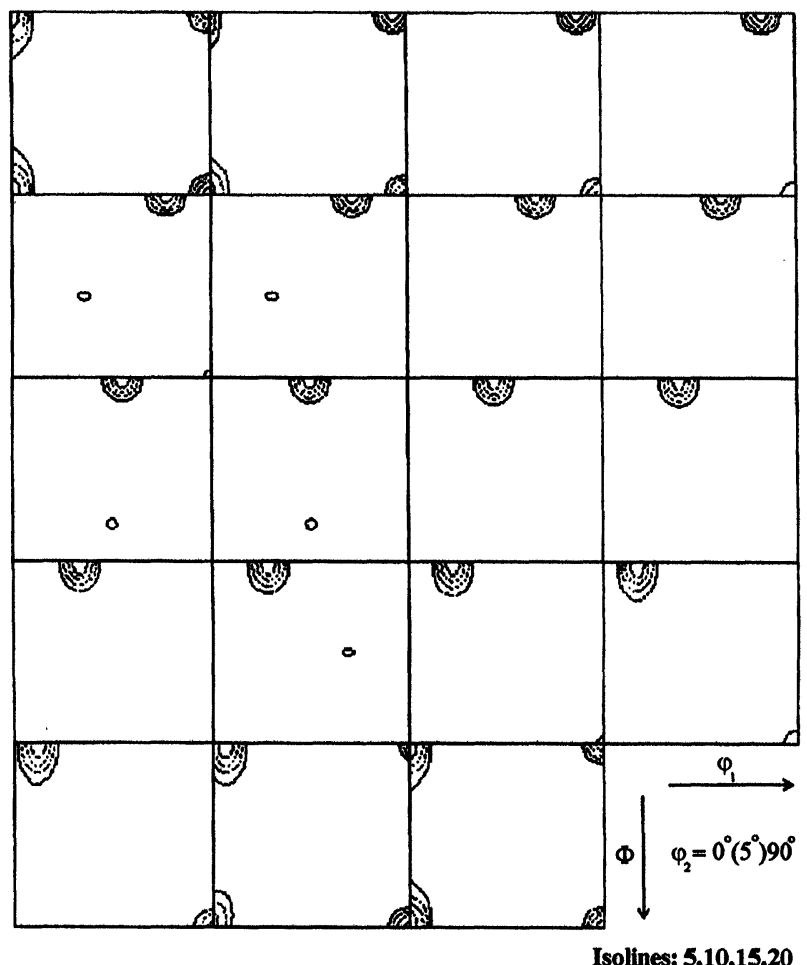

FIGURE 3(b)

FIGURE 3 ODF of $\mathrm{Cu}$ cold rolled and annealed at $250^{\circ} \mathrm{C}$ for $30 \mathrm{~min}$ : ultrafinegrained (a), coarse-grained (b).

of elastic behaviour. It appeared that in the latter case the Young's modulus anisotropy was less pronounced (Fig. 4(a)). An increase in the temperature of annealing led to a gradual change of the isotropic state of the cold rolled ultrafine-grained $\mathrm{Cu}$ that transferred to the distinctly pronounced anisotropic state with maxima at an angle of $45-50^{\circ}$ with respect to the rolling direction (Fig. 4(e)).

\section{DISCUSSION}

As noted before, in the present work an approach based on determination of ODF coefficients by the results of measuring velocities of 

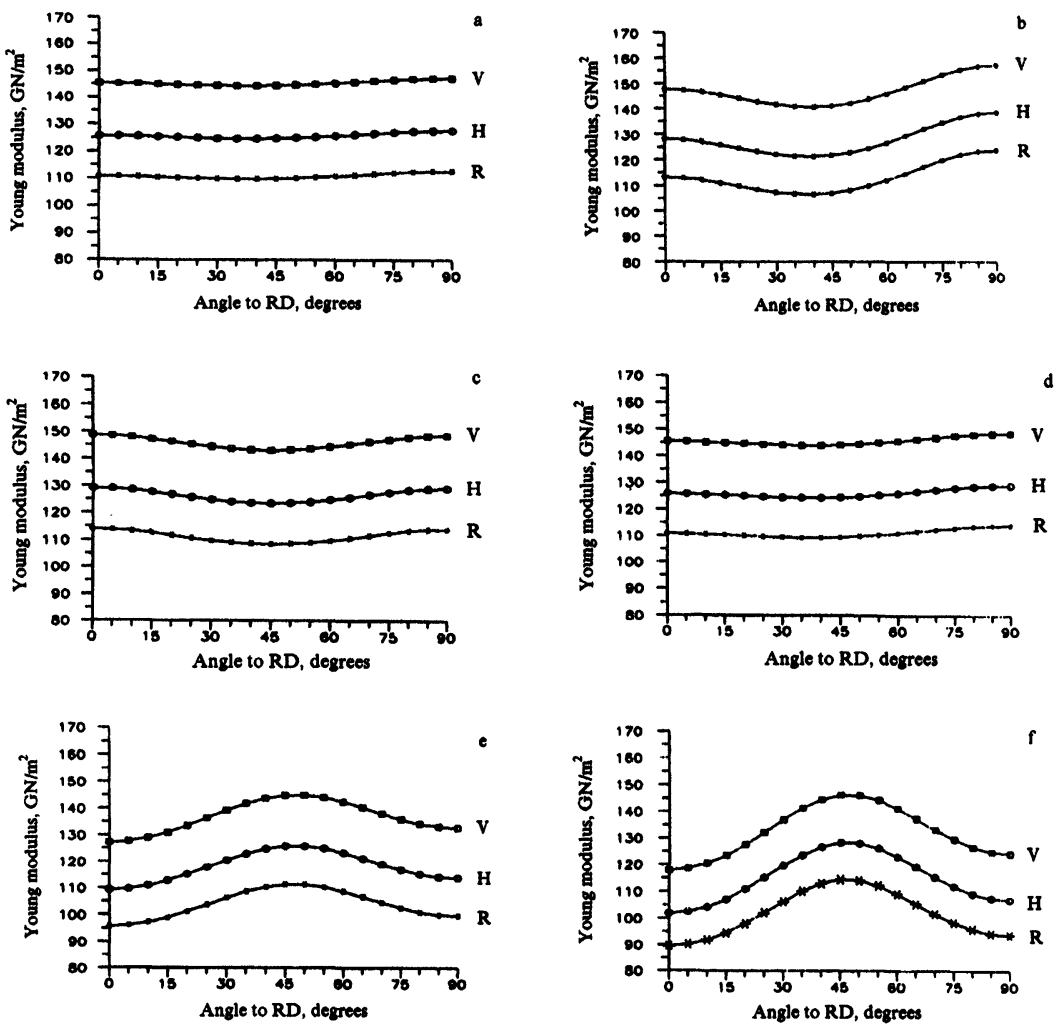

FIGURE 4 Dependence of the Young's modulus on the angle to the rolling direction in the rolling plane calculated in the approximations of Voigt (V), Reuss (R) and Hill (H) for the cold rolled ultrafine-grained $\mathrm{Cu}$ (a) as well as after its annealing for $30 \mathrm{~min}$ at the temperatures, $50^{\circ} \mathrm{C}(\mathrm{b}), 100^{\circ} \mathrm{C} \mathrm{(c),} 150^{\circ} \mathrm{C}$ (d), $200^{\circ} \mathrm{C}(\mathrm{e}), 250^{\circ} \mathrm{C}$ (f).

ultrasonic wave propagation was used for investigating the Young's modulus anisotropy in the rolling plane of cold rolled and annealed sheets of ultrafine-grained and coarse-grained $\mathrm{Cu}$. Previously such an approach proved its reliability at investigations of anisotropy of elastic properties in sheet materials (Serebryany, 1994). The obtained data fit the results of direct measurements of the Young's modulus (Bunge, 1969; Davies et al., 1975; Davies, 1976) and were between upper and lower limits obtained by calculations of the Young's modulus anisotropy for different directions in the rolling plane. The calculations were made reasoning from ODF coefficients in approximations of 

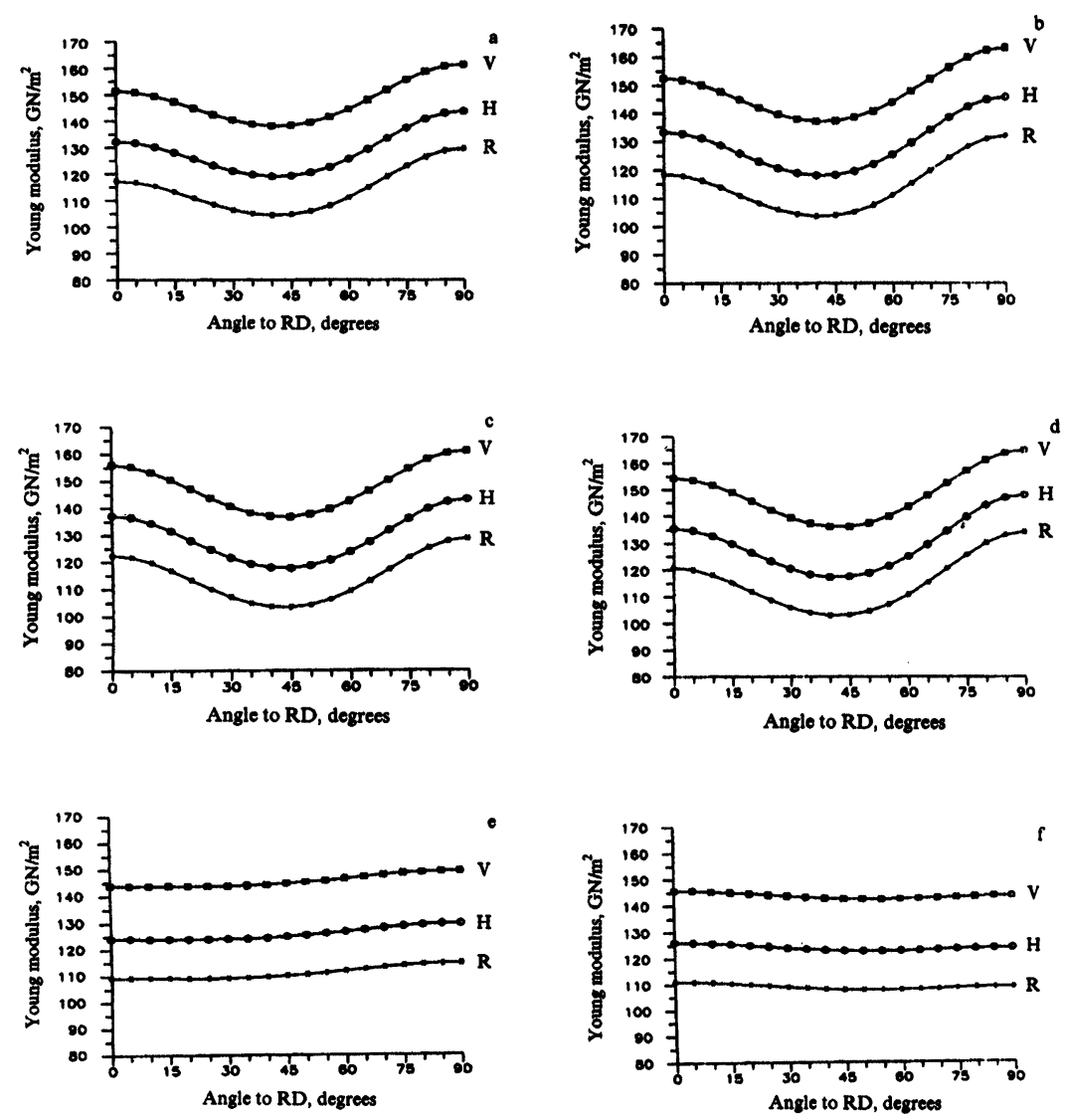

FIGURE 5 Dependence of the Young's modulus on the angle to the rolling direction in the rolling plane calculated in the approximations of Voigt (V), Reuss (R) and Hill $(\mathrm{H})$ for the cold rolled coarse-grained $\mathrm{Cu}$ (a) as well as after its annealing for $30 \mathrm{~min}$ at temperatures, $50^{\circ} \mathrm{C} \mathrm{(b),} 100^{\circ} \mathrm{C}$ (c), $150^{\circ} \mathrm{C}$ (d), $200^{\circ} \mathrm{C}$ (e), $250^{\circ} \mathrm{C}$ (f).

theories of Voigt (similar deformations of grains) and Reuss (similar stresses in different grains). The results obtained by calculations using the Hill theory were the closest to the experimental ones. In the frame of this theory the results obtained by calculations according to theories of Voigt and Reuss were averaged. Thus, it appeared that the established character of the Young's modulus anisotropy in the rolling plane for cold rolled and/or annealed states of the investigated coarse-grained material could be explained by an influence of only one structural factor, namely, a crystallographic texture. 
So, the comparative analysis of the results of the investigations conducted and the known results of direct measurements of the Young's modulus allows us to assume that the approach used in the present work is reliable for calculating the Young's modulus anisotropy in the coarsegrained cold rolled and annealed $\mathrm{Cu}$.

On the other hand, the application of such an approach in the case of the ultrafine-grained cold rolled $\mathrm{Cu}$ revealed abnormality in the Young's modulus anisotropy. In this connection, let us debate about the reliability of the present results and the possibility to apply the given approach to the analysis of anisotropy of elastic properties in such complex objects as ultrafine-grained materials processed by severe plastic deformation.

As known from the above given facts, the crystallographic texture is the main factor providing formation of the distinctly pronounced anisotropy of the Young's modulus in the cold rolled coarse-grained $\mathrm{Cu}$. Thus, let us compare crystallographic texture types formed in coarsegrained and ultrafine-grained $\mathrm{Cu}$ during cold rolling.

The conducted investigations of crystallographic textures formed in ultrafine-grained and coarse-grained $\mathrm{Cu}$ during cold rolling showed that they were similar. The similarity of ODF characters in the studied states was also revealed by Mishin et al. (1996). The comparison with the known literature data (Bunge, 1969; Kallend, 1970) allows us to assume that the obtained crystallographic textures are typical for the coarsegrained cold rolled $\mathrm{Cu}$. The results of modelling of texture formation processes during superplastic deformation (Bunge, 1969; Alexandrov and Kaibyshev, 1984) show that a type of ODF formed in the coarsegrained cold rolled $\mathrm{Cu}$ is provided by crystallographic slip by slip systems of type $\{111\}\langle 110\rangle$. Thus, one can assume that these systems provide formation of the crystallographic texture observed in the coarsegrained and ultrafine-grained $\mathrm{Cu}$ after cold rolling.

Taking into account a similar character of crystallographic textures formed in ultrafine-grained and coarse-grained $\mathrm{Cu}$ during cold rolling, it becomes clear that the almost complete absence of the Young's modulus anisotropy in the rolling plane of the ultrafine-grained $\mathrm{Cu}$ cannot be explained only by the influence of the crystallographic texture that is more intensive in the latter case than in the coarsegrained cold rolled $\mathrm{Cu}$. Thus, one can conclude that there exists another structural factor responsible for the observed absence of the 
Young's modulus anisotropy in the rolling plane of the ultrafinegrained cold rolled $\mathrm{Cu}$.

The previous TEM investigations of structure showed that severe plastic deformation led to formation of ultrafine-grained structure characterised not only by the small grain size but also by the specific defect structure (Valiev et al., 1993). A specific feature of this defect structure consists in appearing extrinsic grain boundary dislocations of high density in grain boundaries. The interface density of these dislocations can reach $1 \mathrm{~nm}^{-1}$. These extrinsic grain boundary dislocations initiate long range fields of internal elastic stresses that significantly distort a crystal lattice, those distortions being specially higher near grain boundaries. As a result, links between atoms in the near grain boundary region become weak and elastic moduli in this region are lower than that within a grain body. So, the obtained results allow us to suggest that low modulus grain boundary regions could be one of the main factor determining a character of the Young's modulus anisotropy in the rolling plane of the ultrafine-grained cold rolled $\mathrm{Cu}$. These regions are responsible for both the decrease in values of elastic moduli and the change in a character of their anisotropy.

Not only the crystallographic texture but also the non-equilibrium state of grain boundaries influence the velocity of elastic wave propagation in ultrafine-grained materials. In this connection, ODF coefficients obtained in the present work on the basis of ultrasonic measurements appear to be distorted by the influence of the defect structure and the calculated anisotropy of the Young's modulus reflects the influence of both the crystallographic texture and the non-equilibrium state of grain boundaries.

Low temperature annealing leads to formation of an absolutely new type of the crystallographic texture in the case of both the coarse-grained and ultrafine-grained $\mathrm{Cu}$. The formed crystallographic texture characterised by a large volume fraction of orientation $\{100\}\langle 001\rangle$ is used to be called "a cubic like texture" (Davies et al., 1975).

The character of the Young's modulus anisotropy in the rolling plane in both studied states has also changed. The distinctly pronounced anisotropy of the Young's modulus is typical for the ultrafine-grained cold rolled $\mathrm{Cu}$ after annealing at $250^{\circ} \mathrm{C}$. Its character significantly differs from the one observed in the state before annealing. At the same time the revealed anisotropy completely fits the results of direct measurements 
as well as the regularities calculated taking into account the leading role of only the crystallographic texture in formation of the Young's modulus anisotropy in the rolling plane of the coarse-grained $\mathrm{Cu}$ (Davies et al., 1975). On the other hand, low temperature annealing of the coarsegrained cold rolled $\mathrm{Cu}$ lead to a weakly pronounced anisotropy of the Young's modulus. A similar phenomenon was also observed experimentally and fit a weakly pronounced crystallographic texture of recrystallization or a partially recrystallized state (Davies et al., 1975; Alexandrov et al., 1985) (Fig. 6).

In the present investigations the intensity of ODF texture maxima of the coarse-grained annealed cold rolled $\mathrm{Cu}$ is less than that of the ultrafine-grained annealed cold rolled $\mathrm{Cu}$ by almost a factor of two. After annealing at $250^{\circ} \mathrm{C}$ the latter also becomes coarse-grained. This makes clear the reasons for formation of the revealed character of the Young's modulus anisotropy in the considered cases.

The present results significantly supplement the results of previous investigations in which the direct measurements of the Young's modulus in the ultrafine-grained $\mathrm{Cu}$ processed by equal channel angular pressing testified its decreased value as compared the coarse-grained state (Akhmadeev et al., 1992). In the same work a decrease in the Young's modulus by $13 \%$ with rising annealing temperature to $125^{\circ}-175^{\circ} \mathrm{C}$ was revealed depending on the purity degree of the studied $\mathrm{Cu}$ samples. As a result, the Young's modulus acquired a value typical for the coarsegrained Cu. Recently (Akhmadeev et al., 1992; 1993; Lebedev et al., 1996a,b) this fact was explained by transformation of non-equilibrium

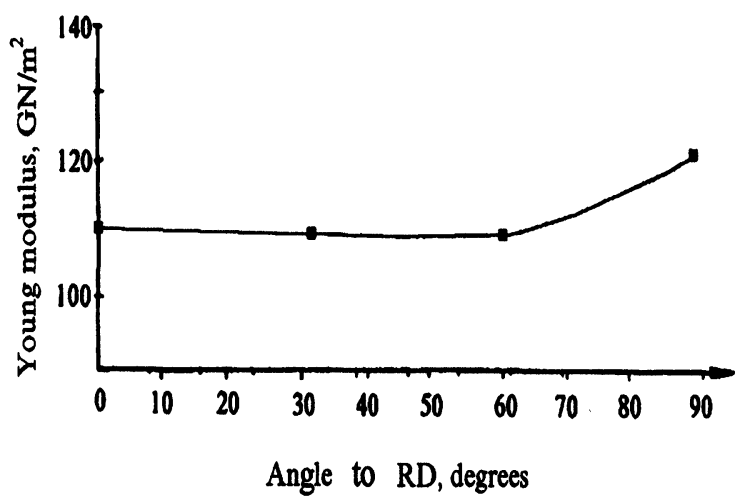

FIGURE 6 Anisotropy of the Young's modulus in the rolling plane of the partially recrystallized $\mathrm{Cu}$ after cold rolling and ultra rapid annealing. 
grain boundaries to an equilibrium state due to grain boundary recovery. In the present investigations the given effect was not observed since in the case of both the coarse-grained and ultrafine-grained $\mathrm{Cu}$ the values of elastic constants typical for the coarse-grained $\mathrm{Cu}$ were taken into account for determination of ODF coefficients.

On the other hand, the results presented in the given work testify a significant role of the crystallographic texture in formation of a level and anisotropy of the Young's modulus in the studied materials. It should be noted that during low temperature annealing at a definite temperature, equal to $150^{\circ} \mathrm{C}$ in the case of $\mathrm{Cu} 99.98 \%$ in purity, a growth of grains with a new orientation begins, i.e. a crystallographic texture is formed that can significantly influence the value of the Young's modulus and its anisotropy. The change in the value of the Young's modulus in $\mathrm{Cu}$ with coarser grains can be also explained by changes in the crystallographic texture.

In order to show the important role of the crystallographic texture in formation of the value of the Young's modulus, let us retrace the evolution of the Young's modulus in the ultrafine-grained and coarsegrained $\mathrm{Cu}$ during low temperature annealing without changing values of elastic constants as temperature increases. At the same time the rolling direction in which the most significant changes in values of the Young's modulus occur should be considered too (Figs. 3 and 4).

The analysis of Fig. 7 shows that a value of the Young's modulus in the rolling direction at first grows within the experiment error limit $( \pm 3 \%)$ and then (after $150^{\circ} \mathrm{C}$ ) starts to drop. Its drop is the steepest during annealing of the cold rolled ultrafine-grained $\mathrm{Cu}$ that corresponds to the onset of grain growth and texture transformation in it.

Thus, it appeared that contrary to the increase of the value of the Young's modulus revealed by Akhmadeev et al. (1993), the significant (by $24 \%$ ) decrease of its value can occur in the ultrafine-grained $\mathrm{Cu}$ at low temperature annealing. This decrease is attributed to the evolution of the crystallographic texture. In the coarse-grained $\mathrm{Cu}$ this tendency is less pronounced; it is evidently connected with non-complete texture transformation of the crystallographic texture at the considered low temperatures of annealing, less pronounced texture maxima testifying this.

The process of severe plastic deformation via equal channel angular pressing is rather complex. During this process the crystallographic texture can change significantly depending on the number of passes and that portion of the sample from which a specimen for structural studies 


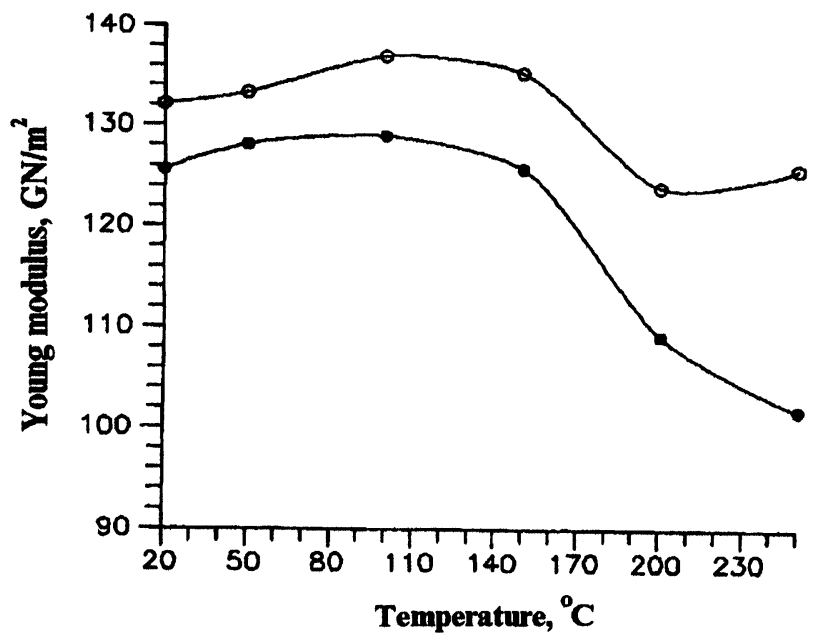

FIGURE 7 Evolution of the Young's modulus in the rolling direction in the cold rolled ultrafine-grained $(\bigcirc)$ and coarse-grained $(O) \mathrm{Cu}$ at increasing annealing temperature.

was cut. In this connection, the texture changes occurring at low temperature annealing can lead to formation of textures distinguished not only by intensity of components but also by their type. On the other hand, the conducted investigations showed that the Young's modulus anisotropy in the cold rolled ultrafine-grained $\mathrm{Cu}$ is less pronounced than in the cold rolled coarse-grained $\mathrm{Cu}$. At the same time the character of the crystallographic texture in these states is almost similar. This testifies the significant role of defect structures in formation of the level and anisotropy of the Young's modulus.

Thus, we can conclude that different factors can influence the character of elastic properties of ultrafine-grained materials and their anisotropy. Estimation of contributions of these factors to the evolution of the Young's modulus during annealing of non-equilibrium ultrafinegrained materials will be an object of future investigations.

\section{CONCLUSIONS}

The conclusions of the present work can be summarised as follows:

1. The Young's modulus anisotropy was investigated in the cold rolled and annealed coarse-grained $\mathrm{Cu}$ based on determination of ODF 
coefficients obtained from the result of measuring velocities of elastic wave penetration. This leads to results analogous to the results of direct measurements.

2. The abnormal character of the Young's modulus anisotropy revealed in the cold rolled and annealed ultrafine-grained $\mathrm{Cu}$ due to application of such an approach testifies that in the given case not only the crystallographic texture but also the low modulus grain boundary phase play a significant role in formation of elastic properties.

\section{Acknowledgements}

This research was partially supported by Russian Foundation for Basic Research and Bashkir Academy of Sciences, Ufa, Russia. This material is in part based upon work supported by the U.S. Civilian Research and Development Foundation under Award No. RE2-164. The authors thank Prof. Y.D. Wang for providing texture investigations obtained by modified maximum entropy method.

\section{References}

Akhmadeev, N.A., Valiev, R.Z., Kobelev, N.P., Mulyukov, R.R. and Soifer, Ya.M. (1992). Elastic properties of copper with submicrocrystalline structure. Solid State Physics, 34, 3155-3160.

Akhmadeev, N.A., Kobelev, N.P., Mulyukov, R.R., Soifer, Ya.M. and Valiev, R.Z. (1993). The effect of heat treatment on the elastic and dissipative properties of copper with the submicrocrystalline structure. Acta Metall. Mater., 1993, 41, 1041-1046.

Alexandrov, I.V. and Kaibyshev, O.A. (1984). Method of computer simulation of texture formation processes in plastic deformation. Industrial laboratory, 50 9, 43-46.

Alexandrov, I.V. and Davies, G.J. (1985). Texture development in the ultrarapid annealing of cold-rolled copper and steel. Mater. Sci. Engineer., 75, L1-L4.

Alexandrov, I.V., Wang, Y.D., Zhang, K., Lu, K. and Valiev, R.Z. (1996a). X-ray analysis of the textured nanocrystalline materials. Proceedings of the Eleventh International Conference on Textures in Materials, 2, pp. 929-940. Beijing: International Academic Publishers.

Alexandrov, I.V., Serebryany, V.N. and Sarvarova, L.N. (1996b). Comparative analysis of the formation of the elastic properties anisotropy in the different structural states of copper. Abstracts of the VII International Seminar "Structure, defects and properties of nanocrystalline, ultrafinedisperse and multilayered materials", 2, pp. 123-124. Ekaterinburg, Russia, in Russian.

Alexandrov, I.V., Zhang, K., Lu, K. and Valiev, R.Z. (1997). Comparative X-ray analysis of nanocrystalline materials, processed by severe plastic deformation. Nanostructured Materials, 9, 347-354.

Allen, D.R. and Sayers, C.M. (1984). The measurement of residual stress in textured steel using an ultrasonic velocity combinations technique. Ultrasonics, 22(4), 179-184. 
Bunge, H.J. (1968). Uber die elastischen konstanten kubischer materialien mit beliebiger textur. Kristall und Technik, 3, 431-438.

Bunge, H.J. (1969). Mathematische Methoden der Texturanalyse. Berlin: Akademie Verlag, 330.

Davies, G.J., Kallend, J.S. and Ruberg, T. (1975). Quantitative textural measurements on cube-texture copper. Metal Science, 9, 421-424.

Davies, G.J. (1976). Texture analysis and anisotropy in metals. J. Metals Research, 28, 21-28.

Iwahashi, Y., Horita, Z., Nemoto, M. and Langdon, T.G. (1998). The process of grain refinement in equal-channel angular pressing. Acta Materialia, 46, 1589-1599.

Kallend, J.S. (1970). Quantitative analysis of texture data. Ph.D. thesis. Cambridge.

Langford, G. and Cohen, M. (1969). Microstructure of Armco-iron subjected to severe plastic deformation. Trans. ASM, 82, 623-632.

Lebedev, A.B., Burenkov, Yu.A., Pulnev, S.A., Vetrov, V.V. and Kopylov, V.I. (1969a). Recovery of Young's modulus during annealing of submicrocrystalline $\mathrm{Cu}$ and $\mathrm{Cu}$ : $\mathrm{ZrO}_{2}$ composite. Journale de Physique IV, C8, 365-368.

Lebedev, A.B., Pulnev, S.A., Kopylov, V.I., Burenkov, Yu.A., Vetrov, V.V. and Vylegzhanin, O.V. (1969b). Thermal stability of submicrocrystalline copper and $\mathrm{Cu}$ : $\mathrm{ZrO}_{2}$ composite. Scripta Materialia, 35, 1077-1081.

Mishin, O.V., Gertsman, V.Yu. and Gottstein, G. (1996). Texture and grain boundary distributions in ultrafine-grained copper. Proceedings of the Eleventh International Conference on Textures in Materials, 2, pp. 1015-1020. Beijing: International Academic Publishers.

Mulyukov, R.R., Akhmadeev, N.A., Valiev, R.Z., Kopylov, V.I. and Mikhailov, S.B. (1993). Amplitude dependence of internal friction and strength of submicrocrystalline copper. Metallophysica, 15, 50-58.

Öztürk, T. (1978). The development of annealing textures in F.C.C. metals and alloys. Ph.D. thesis. Cambridge.

Pavlov, V.A. (1989). Amorphisation during intense rolling. Phys. Metal. Metallurg., 67, 924-932.

Pospiech, J. and Lücke, K. (1975). The rolling textures of copper and $\alpha$-brasses in terms of the orientation distribution function. Acta Metall., 23, 997-1007.

Ruberg, T. (1978). Texture development in some face centered cubic metals and the relation of texture to properties. Ph.D. thesis. Cambridge.

Rybin, V.V. (1986). Large plastic deformation and fracture of metals. Moscow: Metallurgia Publ., 279.

Sayers, C.M. (1982). Ultrasonic velocities in anisotropic polycrystalline aggregates. J. Phys. D: Appl. Phys., 15, 2157-2167.

Segal, V.M., Reznikov, V.1., Drobyshevskij, A.E. and Kopylov, V.I. (1981). Equal channel angular extrusion. Russian Metally, 1, 99-105.

Serebryany, V.N. (1994). Quantitative estimation of the texture in the steel sheets by ultrasonic volume waves. Industrial laboratory, 4, 29-33, in Russian.

Serebryany, V.N. (1996). Plastic anisotropy prediction by ultrasonic texture data. Textures and Microstructures, 25, 223-228.

Valiev, R.Z., Korznikov, A.V. and Mulyukov, R.R. (1993). Structure and properties of ultrafine-grained materials. Mater. Sci. Engineer., A168, 141-148.

Valiev, R.Z., Kozlov, E.V., Ivanov, Yu.F., Lian, J., Nazarov, A.A. and Baudelet, B. (1994a). Deformation behavior of ultrafine-grained copper. Acta Metall. Mater., 42, 2467-2473.

Valiev, R.Z. and Musalimov, R.Sh. (1994b). High resolution transmission electron microscopy. Phys. Metal. Metall., 78, 666-670 (in Russian).

Valiev, R.Z. (1997). Structure and mechanical properties of ultrafine-grained metals. Mater. Sci. Engineer., A234-236, 59-66. 
Ultrafine-grained materials prepared by severe plastic deformation (1996). Special issue of Annales de Chimie. Science des Materiaux, ed. by R.Z. Valiev, pp. 369-520. Paris: Masson.

Zhang, K., Alexandrov, I.V., Valiev, R.Z. and Lu, K. (1996). The structural characterization of nanocrystalline $\mathrm{Cu}$ by means of the X-ray diffraction. J. Appl. Phys., 21, $407-416$.

Wang, Y.D., Xu, J.Z., Zuo, L., Liang, Z.D., Vadon, A., Bessierer, J. and Heitzmann, J.J. (1996). Some applications of the modified maximum entropy method in quantitative texture analysis. Proceedings of the Eleventh International Conference on Textures in Materials, 2, pp. 1064-1069. Beijing: International Academic Publishers. 